\title{
O tema violência intrafamiliar na concepção dos formadores dos profissionais de saúde
}

\author{
Domestic violence in the conception of health professionals trainers
}

Edinilsa Ramos de Souza ${ }^{1}$

Adalgisa Peixoto Ribeiro ${ }^{2}$

Lúcia Helena Garcia Penna ${ }^{3}$

Ana Lúcia Ferreira ${ }^{4}$

Neuci Cunha dos Santos ${ }^{5}$

Claudia M ara de M elo Tavares ${ }^{6}$

${ }^{1}$ Departamento de

Epidemiologia e M étodos

Quantitativosem Saúde,

Centro Latino-Americano de

EstudosdeViolênciaeSaúde,

Escola Nacional deSaúde

Pública. Av. Brasil, 4036/700,

Manguinhos. 21040-061 Rio

deJaneiro RJ.

edinilsa@claves.fiocruz.br

${ }^{2}$ Centro Latino-Americano

deEstudos deViolênciae

Saúde, Escola Nacional de

SaúdePública.

${ }^{3}$ Departamento de

Enfermagem M aterno-

Infantil, Faculdadede

Enfermagem, Universidade

Estadual do Rio dejaneiro.

${ }^{4}$ Departamento dePediatria,

FaculdadedeM edicina,

UniversidadeFederal do Rio

deJaneiro.

${ }^{5}$ FaculdadedeEnfermagem,

UniversidadeFederal de

$M$ ato Grosso.

${ }^{6}$ Departamento de

Enfermagem $M$ aterno-

Infantil e Psiquiatria, Escola

deEnfermagem,

UniversidadeFederal

Fluminense
Abstract This article identifies the conceptions and suggestions of professors of medicine and nursing courses about the insertion of this subject in the formation of their students. An exploratory research was carried out using a questionnaire applied to coordinators of disciplines in such courses at public and private universities in the cities of Rio de Janeiro and Cuiabá. M any of them recognizes violence asa health problem, although $40.7 \%$ of medicineprofessors and $71.1 \%$ of nursing professors of the two cities discusses this subject in their classes. The medicine professors suggests the insertion of the violence subject in their students formation with visits to institutions, meeting groups with people in violence situations and interviews with experienced professionals of the area. The nursing professors prefer re sources such as films and videos, seminaries and conferences. Gaps were also identified in the students and professors formation, which do not feel able to discuss this thematic. It is indicated that a renovation in the curriculum is urgently necessary.

Key words Domestic violence, Formation, Education, Training
Resumo Esteartigo tem o objetivo de identificar as concepções e sugestões dos docentes de graduação de medicina e enfermagem sobre a inserção do tema violência intrafamiliar na formação dos alunos. Realizou-se uma pesquisa exploratória aplicandose questionário a coordenadores de disciplinas de universidades públicas e particulares desses cursos nas cidades do Rio de Janeiro e de Cuiabá. A maioria dos professores reconhece a violência como problema desaúde, embora $40,7 \%$ da medicina e71,1\% da enfermagem nas duas cidades a abordem em suas aulas. Docentes de medicina sugerem a inserção transversal do tema na formação dosalunos por meio de visitas a instituições, grupos de encontro com pessoas em situação de violência e entrevista com profissionais experientes no tema. Os de enfermagem apostam em recursos como filmes e vídeos, se minários e conferências. I dentificaram-se lacunas na formação dos alunos e dos professores que não se sentem capacitados para discutir a temática da violência. Indica-se necessidade de mudanças urgentes nos currículos desses cursos.

Palavras-chave Violência intrafamiliar, Formação, Ensino, Treinamento 


\section{Introdução}

A violênciaintrafamiliar, amplamenteidentificada como negligência e abuso de crianças eadolescentes, violência doméstica contra mulheres, maus tratos de idosos e de pessoas portadoras de deficiência, atinge parcelas importantes da população e tem impacto significativo no bem-estar físico, emocional esocial deindivíduose comunidades. Constitui um problema relevantede saúde pública eum desafio para o Sistema Ú nico de Saúde (SUS) no que diz respeito à organização de serviços e gestão de recursos humanos.

Estudos têm reconhecido que os profissionais de saúde, pela posição que ocupam na prestação de serviços à população, são consi derados essenciais na identificação deindivíduos egrupos populacionais de risco para a violência e para a execução de iniciativas que promovam a prevenção e as intervenções mais adequadas ${ }^{1-4}$.

Entretanto, a crescente necessidade de atendimento às vítimas de violência que chegam aos serviços de saúde, quevem ocorrendo a partir de 1980 no Brasil|5,6, evidencia debilidades estruturais do sistema de saúde e dificuldades de seus profissionais no atendimento e acompanhamento dessas pessoas. Tudo isso contribui para a reincidência e agravamento de casos, pela falta de implementação de medidas preventivas e de intervenções apropriadas. Certamente, muitos desses problemas estão relacionados ao processo de formação e capacitação dos membros das equipes de saúde.

A maior parte dos estudos que abordam a questão da capacitação de profissionais da saúde em relação à violência indica a necessidade de se desenvolver estratégi as para instruí-los sobre o tema. É recorrentenestes estudos o relato de que os professores, alunos e profissionais da saúde reconhe cem a importância do problema da violência intrafamiliar ${ }^{7-10}$. Investigações realizadas em comunidade médica, além de identificarem o aumento da consciência dos médicos sobre a violência doméstica e de recursos disponíveis para a sua abordagem, indicam também a necessidade de introduzir formalmente o tema nos currículos e desenvolver programas de capacitação permanente das equipes de saúde ${ }^{11-13}$.

No Brasil, o M inistério da Saúde tem elaborado manuais técnicos e políticas públicas sobre 0 assunto desde a década de noventa, dentre os quais se destacam a Política Nacional de Redução da M orbimortalidadepor Acidentes eViolências (PN RM AV), publicada na Portaria M S/GM no 737 de 16/ 05/2001'14, a Portaria no 936/GM, de 2004, que dispõe sobre a estruturação da Rede Nacional de Pre- venção da Violência e Promoção da Saúde e a implantação e implementação de Núcleos de Prevenção à Violência em Estados e Municípios ${ }^{15}$ e o Caderno de Atenção Básica $n^{\circ} 8$, Violência intrafamiliar - Orientaçõ̃es para a Prática em Serviço ${ }^{16}$. M ais recentemente, a Política Nacional de Promoção da Saúde, promulgada na Portaria M S/GM n ${ }^{\circ} 687$ de $30 / 03 / 2006^{17}$, reafirma a nova posição do setor saúde, pois além de incluir oficialmente a violência em sua agenda, assume a competência em ordenar a formação de recursos humanos neste tema.

M esmo considerando o esforço do setor saúde em recomendar as ações e práticas de diagnóstico, tratamento e prevenção da violência intrafamiliar e a fixação de diretrizes referentes à capacitação de recursos humanos em relação à implantação da política específica, as alterações curriculares nesta direção ainda são lentas, pontuais e pouco conhecidas.

0 objetivo deste artigo é identificar as concepções dos docentes de graduação de medicina e enfermagem sobrea inserção do tema violência intrafamiliar na formação dos alunos/profissionais de saúde e as sugestões que dão para sua abordagem.

\section{M etodologia}

Este trabalho é parte de uma pesquisa exploratória cujo objetivo maior foi investigar a inserção do tema violência intrafamiliar nos cursos de enfermagem emedicina deduas grandes cidades ondea violência encontra-se marcadamente presente: Cuiabá e Rio de Janeiro. 0 recortefeito no presente artigo se refere às concepções dos docentes dos referidos cursos, sobre a violência intrafamiliar como tema necessário na formação desses profissionais de saúde.

O cenário da pesquisa foi constituído por instituições de ensino superior de enfermagem e medicina dos municípios do Rio de Janeiro e Cuiabá. A escolha das universidades em cada capital foi feita a partir da modalidade administrativa (federal, estadual e particular) e da tradição e tempo de implantação dos cursos.

Inicialmente, na análise dos currículos, foram identificadas 99 disciplinas nas quais havia a presença do termo violência ou algum outro termo correlato, sendo 58 nos cursos de medicina e 41 nos de enfermagem. Foram considerados termos correlatos à violência: traumas, acidentes, drogas, causas externas, justiça/injustiça social, direitos, exclusão, desigualdades, pobreza/miséria, entre outros, por representarem temas que poderiam gerar discussões sobre a questão da violência nas disciplinas. 
Para os cursos de enfermagem, a totalidade dos coordenadores das disciplinas identificadas respondeu ao questionário, mas nos curso de medicina, apenas $45 \%$ deles o responderam, totalizando 67 docentes participantes. Os professores se distribuíram da seguinteforma: 26 professores dos cursos de medicina e 41 dos cursos de enfermagem; 49 professores dos cursos do Rio de Janeiro e 18 dos de Cuiabá e, finalmente, 48 eram professores das instituições públicas e 19 das universidades particulares.

0 instrumento de pesquisa, construído para captar as concepções acerca do tema da violência intrafamiliar e sua inserção nos currículos desses cursos de graduação, era auto-aplicável e continha três questões abertas e doze fechadas.

As informações foram processadas em um banco de dados no programa EpiData versão 3.1. A fim de minimizar os erros na fase de digitação e agilizar a inserção dos questionários no banco de dados, estes foram codificados, atribuindo valores numéricos às categorias de cada item. A pós a digitação, foi efetuada a crítica para verificar se havia algum erro na codificação ou digitação. Os questionários revistos nesta etapa foram $10 \%$ do total, selecionados por amostragem aleatória simples. Não foram constatados erros nesta amostra.

Para a análise dos dados, foi utilizado o programa SPSS versão 13.0, no qual foram calculadas as frequências simples e relativas e as análises uni e bivariadas das questões fechadas e variáveis de interesse. Os dados foram comparados em função do curso (enfermagem ou medicina) e do município pesquisado (Rio de Janeiro e Cuiabá).

A fim de verificar diferenças estatisticamente significativas, foi utilizado o teste exato de Fisher, que permite calcular a probabilidade de associação das características que estão em análise. Este testeéusado em tabelas de contingência $2 \times 2$, quando o número de dados totais é pequeno e quando há frequências esperadas menores que cinco. 0 teste qui-quadrado foi aplicado apenas nos casos em que não havia frequências esperadas menores que cinco. A penas são indicadas no texto diferenças significativas a $5 \%$ e $10 \%$.

Do ponto de vista qualitativo, a pesquisa buscou captar as sugestões dos professores, em questões abertas do questionário sobre que ações consideravam que a sua faculdade tem condições de desenvolver para preparar o aluno na prática de atenção e prevenção da violência intrafamiliar. Finalmente, foi investigado que lacunas existem na formação do aluno/profissional de saúde em relação a abordagem do tema. As questões suscitavam respostas diretas ea análise buscou, dentre a diversidade das opiniões, aquelas que convergiam, agrupan- do-as em torno de eixos comuns. As opiniões assim agrupadas foram mescladas com as informações obtidas nas questões fechadas do questionário, ora reforçando-se, ora contradizendo-se mutuamente.

0 estudo contou com o apoio do CNPq e foi aprovado pelo ComitêdeÉtica da Escola Nacional de Saúde Pública da Fundação O swaldo Cruz, em cumprimento aos preceitos da Resolução no 196/ 96 do Conselho Nacional de Saúde.

\section{Resultados ediscussão}

Perguntados se conheciam a Política Nacional de Redução da Morbimortalidade por Acidentes e Violências (PNRM AV), lançada pelo M inistério da Saúde em 2001, a grande maioria dos docentes das faculdades de Cuiabá aqui pesqui sadas respondeu afirmativamente a essa questão. Como se pode ver no Gráfico 1, os professores dos cursos do Rio de Janeiro e principalmente os docentes de medicina são os que menos conhecem a PNRM AV.

Recente pesquisa realizada em cinco cidades brasileiras traçou um diagnóstico situacional sobre a estrutura e organização da rede de serviços do SUS para atender às vítimas de acidentes e violência ${ }^{18}$ e identificou que parte dos gestores informava na entrevista que conhecia a PN RM AV, mas posteriormente ficava evidente que não.

A quase totalidade dos docentes das duas cidades reconhece que a violência intrafamiliar é um problema de saúde, com proporções menores entreos professores das faculdades demedicina situadas no Rio de Janeiro. Apesar dessa crença, afirmam, em proporções bem menores, que discutem a questão da violência em suas disciplinas e, nesse caso, os cursos de medicina dos dois municípios são os que menos o fazem ( $42,1 \%$ entre os cariocas e $37,5 \%$ entre os cuiabanos).

0 curso de enfermagem foi o que apresentou maior proporção de professores que abordam 0 tema da violência em suas aulas: $62,1 \%$ no Rio de Janeiro e $100 \%$ em Cuiabá, com diferença estatisticamente significativa $(p=0,038)$ entre as cidades. Em Cuiabá, encontramos ainda uma diferença significativa $(p=0,009)$ com os professores de enfermagem afirmando, mais que os de medicina, que abordam o tema nas disciplinas.

Este fato pode ser explicado através de algumas questões, entre elas o despertar da enfermagem brasileira para as questões sociais nos anos setenta, a afirmação da enfermagem como prática social nos anos oitenta e os desafios assumidos pela profissão diante das transformações sociais mundiais nos anos noventa ${ }^{19}$. 


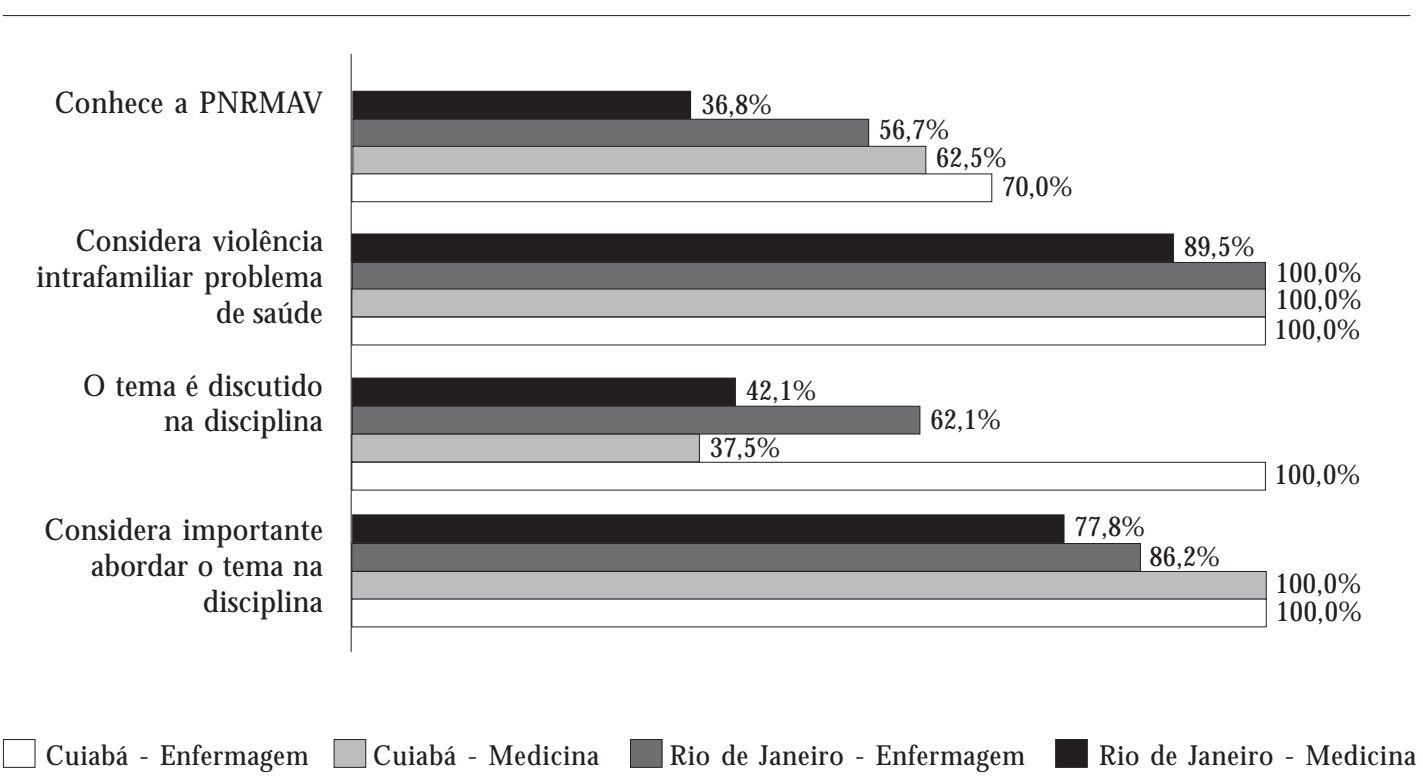

Gráfico 1. Distribuição proporcional das percepções dos docentes sobre o tema da violência intrafamiliar, segundo cidade e curso.

Apesar da maior abertura da enfermagem em relação à inserção da violência na formação de seus profissionais, Penna ${ }^{20}$ discute que os docentes têm muitas dificuldades em incluir essa temática nos planejamentos curriculares. A autora argumenta que os professores que não tiveram contato científico e crítico com o tema e não receberam capacitação tendem a adotar um comportamento de reprodução simbólica das experiências de sua própria formação acadêmica, o que não quer dizer que eles não estejam sensibilizados para a temática.

Isso fica claro quando observamos, no mesmo Gráfico 1, que a grande maioria dos professores de ambos os cursos e cidades concordam que é importante discutir em suas disciplinas o tema da violência.

A literatura internacional também confirma os achados do presente trabalho. Em uma pesquisa realizada nas faculdades de enfermagem dos EstadosU nidos, com o objetivo deidentificar nos currículos a presença de conteúdos sobre violência contra criança, mulher e idoso, os resultados mostraram que ainda existe a necessidade de mudanças para a incorporação desse tema nesses cursos. A maioria das faculdades (63\%) não desenvolve atividades educativas para a abordagem da questão durante os quatro anos de curso, mesmo sendo uma necessidade indicada. M ais de dois terços dos programas (68\%) não avaliam sistematicamente o conteúdo de violência e $75 \%$ não desenvolvem competências com foco na violência entre os alunos ${ }^{21}$.

Pursley e colaboradores ${ }^{22}$, em estudo que buscou analisar as percepções de 86 residentes de medicina da Universidade de Kentucky (Estados Unidos), identificaram que $26 \%$ eram incapazes de descrever dois fatores para a detecção, triagem e tratamento de pacientes envolvidos com a violência doméstica.

$\operatorname{Costa}^{23}$ discuteque, para uma formação de alunos/profissionais de saúde fundamentada na contextualização social, com instrumentos para enfrentar os problemas de saúde da população, são necessários o perfil do aluno, o conteúdo disciplinar emetodologias pedagógicas que levem os profissionais a exercerem uma ação eficaz. Além desses requisitos, deve-se considerar também os "cenários pertinentes à formação", que segundo o autor se formam conjugando a articulação da prática com a realidade social eas necessidades de saúde da população. Ao lado disso, também está o cotidiano vivencial, que direciona as práticas deensino e investigação com vistas a contribuir para a meIhoria da qualidade de vida das pessoas.

Pensando em formas de incorporar o tema violência intrafamiliar nos cenários de formação dos médicos e enfermeiros, os docentes dos cursos e 
cidades aqui investigados apresentaram suas sugestões em relação aos recursos didáticos teóricopráticos ea melhor forma de absorver o tema nos currículos de graduação desses profissionais que são a base da equipe de saúde para atendimento na rede SUS.

0 Gráfico 2 mostra queos professores deCuiabá apostam mais nos recursos de grupos de encontro com pessoas em situação de violência, filmes e vídeos, assim como na experiência de outros profissionais que trabal ham no atendimento a essas pessoas, enquanto os cariocas também investem suas expectativas nos filmes e vídeos, nos con- tatos com profissionais que atendem a vítimas e em seminários e conferências. Vale ressaltar que as estratégias de ensino que envolvem a participação de usuários e profissionais de serviços remetem para uma maior integração entre as instituições de ensino e de prestação de serviços, e esta parece ser uma possibilidade mais viável na percepção dos professores cuiabanos.

Os docentes dos cursos de medicina, de ambas as cidades, concentraram suas sugestões em atividades mais tradicionais voltadas para a academia e para o contato com outros profissionais que trabalham com o tema, incluindo seminários, entre-

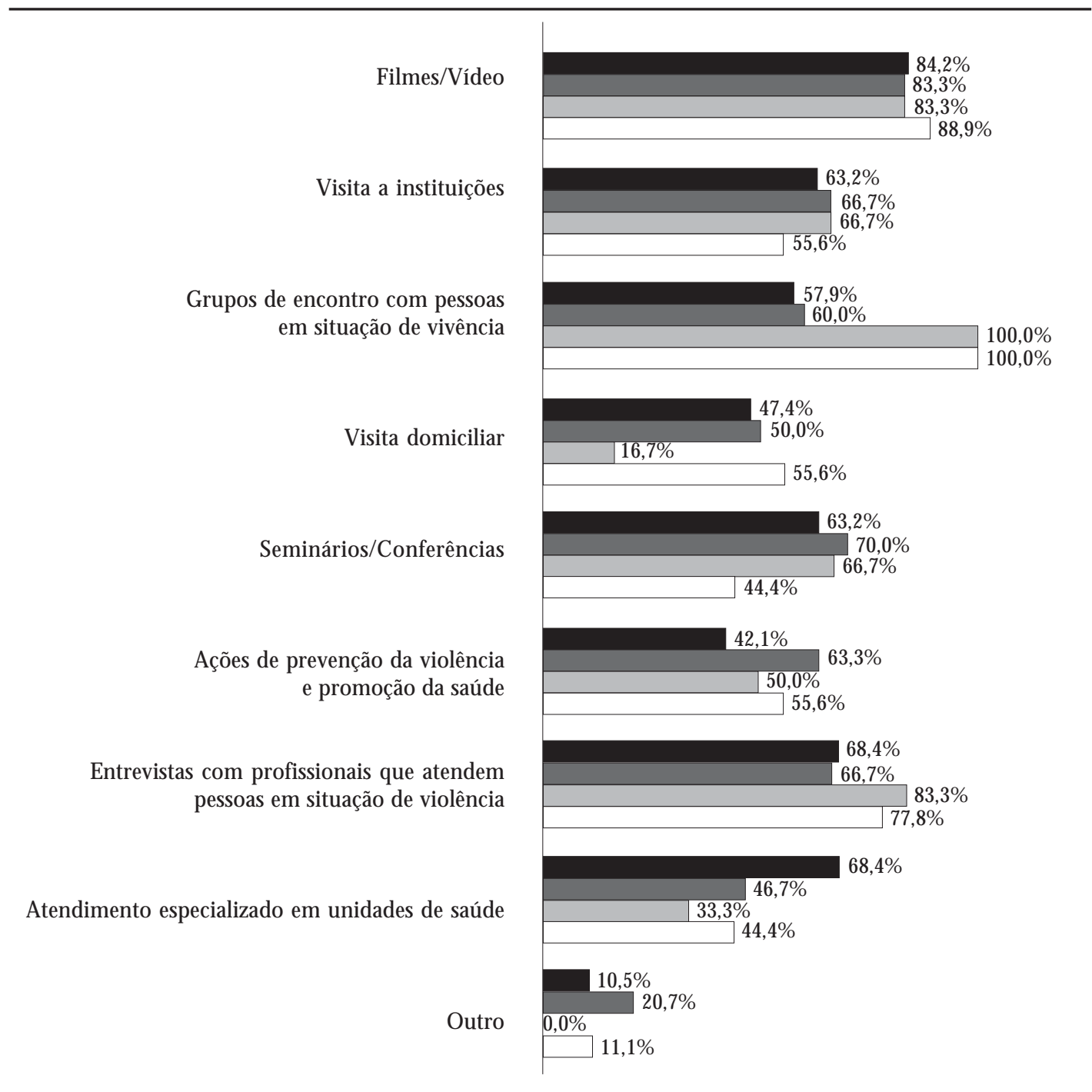

Rio de Janeiro - Medicina

Rio de Janeiro - Enfermagem

Cuiabá - M edicina

Cuiabá - Enfermagem

Gráfico 2. Distribuição proporcional das sugestões dos docentes sobre recursos teórico/práticos para ajudar na formação dos alunos, segundo cidade e curso. 
vistas e visita a instituições. Já os que trabalham nos cursos de enfermagem apostam em recursos mais alternativos como filmes, vídeos, visita domiciliar ea instituições que prestam atendimento a esse público, ações de prevenção e promoção da saúde. Estes achados vêm reforçar as análises anteriores desta pesquisa relativas aos currículos, demonstrando que algumas inovações e incorporações de temas e recursos metodológicos estão se processando na formação dos enfermeiros, certamente pelas novas diretrizes curriculares nacionais ${ }^{14}$, mas também pela defesa da enfermagem como prática social e inserção do ensino de enfermagem no campo da pedagogia crítica. Esta forma de assimilação dos conhecimentos parece ser mais condizente com a teoria crítica da educação e com as abordagens recomendadas para a atuação frenteà violência.

Estenovo modelo deformação busca uma prática social crítica e transformadora dos profissionais da área da saúde frente aos fenômenos sociais que interferem diretamente sobrea saúde das pessoas, como, por exemplo, as situações de violência. Tem sua base calcada na teoria crítica da educação, em que a idéia principal consisteem buscar construir dial ogicamente com os diversos segmentos da sociedade estratégias de transformação da realidade a partir dos reais problemas apontados pelos mesmos.

Como podemos observar no Gráfico 2, os docentes de medicina cuiabanos acreditam mais que os cariocas no recurso dos grupos deencontro com pessoas em situação de violência, com uma diferença significativa entreeles $(p=0,062)$.

Alguns dos entrevistados sugeriram outros re cursos, dentre os quais visita a delegacias e emergências hospitalares, apropriação de conteúdo teórico acerca do assunto, abertura de estágio na área, conhecimento da legislação sobre o tema, contato com movimentos sociais que abordem a questão, grupo vivencial e/ou de dramatização.

A educação básica sobre a violência intrafamiliar foi outro recurso apontado, o que pode ser entendido como um conhecimento a ser obtido no ensino fundamental e/ou médio ou desde os primeiros períodos da graduação. Essa mesma questão érecomendada no texto da Política Nacional de Redução da M orbimortalidade por Acidentes eViolência ${ }^{24}$.

Os professores dos cursos de enfermagem (63,3\% no Rio de Janeiro e 80,0\% em Cuiabá) eda medicina de Cuiabá $(42,9 \%$ ) preferem que o tema da violência intrafamiliar seja incorporado na formação dos alunos/profissionais de saúde como conteúdo transversal nas disciplinas do currículo e nas disciplinas com conteúdos correlatos. Os que atuam nos cursos de medicina na cidade do Rio de Janeiro $(68,4 \%)$ querem que o tema seja abordado nas disciplinas de conteúdos correlatos e, nesse item, observamos uma diferença significativa $(p=0,095)$ entre os médicos das duas cidades e entreos cursos da cidade do Rio de aneiro $(p=0,086)$.

Vale a pena destacar a pouca aprovação dos docentes em relação à abordagem do tema como disciplina obrigatória ou eletiva, como mostra 0 Gráfico 3. A diferença entre os médicos das duas cidades em relação a essa questão foi significativa $(p=0,065)$, com os cuiabanos seapresentando mais favoráveis à obrigatoriedade.

Os achados acima demonstram que os professores não recomendam que o tema seja abordado na forma de uma disciplina, mas grande parcela deles acha que ela deve ser inserida transversalmente. Entretanto, ébom lembrar que, mesmo com esse posicionamento, a análise dos currículos, realizada anteriormente nesta pesquisa, mostrou que a inserção do tema ainda é incipiente: a violência somente foi explicitada ou apareceu na forma de outro termo correlato em $23 \%$ das disciplinas dos cursos de medicina e em $16,3 \%$ das disciplinas dos de enfermagem.

Convém destacar que, ao incorporar esse tema de forma não obrigatória e transversal mente, corre-se o risco do mesmo continuar sendo pouco abordado e na dependência de professores já sensibilizados. Assumi-lo enquanto temática obrigatória em algumas disciplinas significa dar-Ihe a devida importância, priorizá-lo na formação dos alunos e também é uma forma de pressionar os docentes para que busquem se capacitar.

Como observamos nos dados até aqui apresentados, a violência ainda é um tema pouco discutido na formação dos alunos que futuramente atuarão como profissionais de saúde no SUS atendendo à grande demanda de pessoas que sofrem as consequências da violência intrafamiliar.

Esse tema parece que ainda não foi incorporado na prática das pessoas que atuam nos serviços e também dos formadores desses profissionais. Isso se torna mais claro quando observamos os dados mostrados no Gráfico 4. Perguntados sobre quais seriam os recursos que os coordenadores de disciplinas consideravam importantes para ajudar na formação dos alunos, as respostas de mais de $80 \%$ deles se concentraram na opção da capacitação dos docentes com cursos de atualização, especialização e educação permanente. Esse achado mostra que os professores não se sentem aptos a lidar com a questão. 


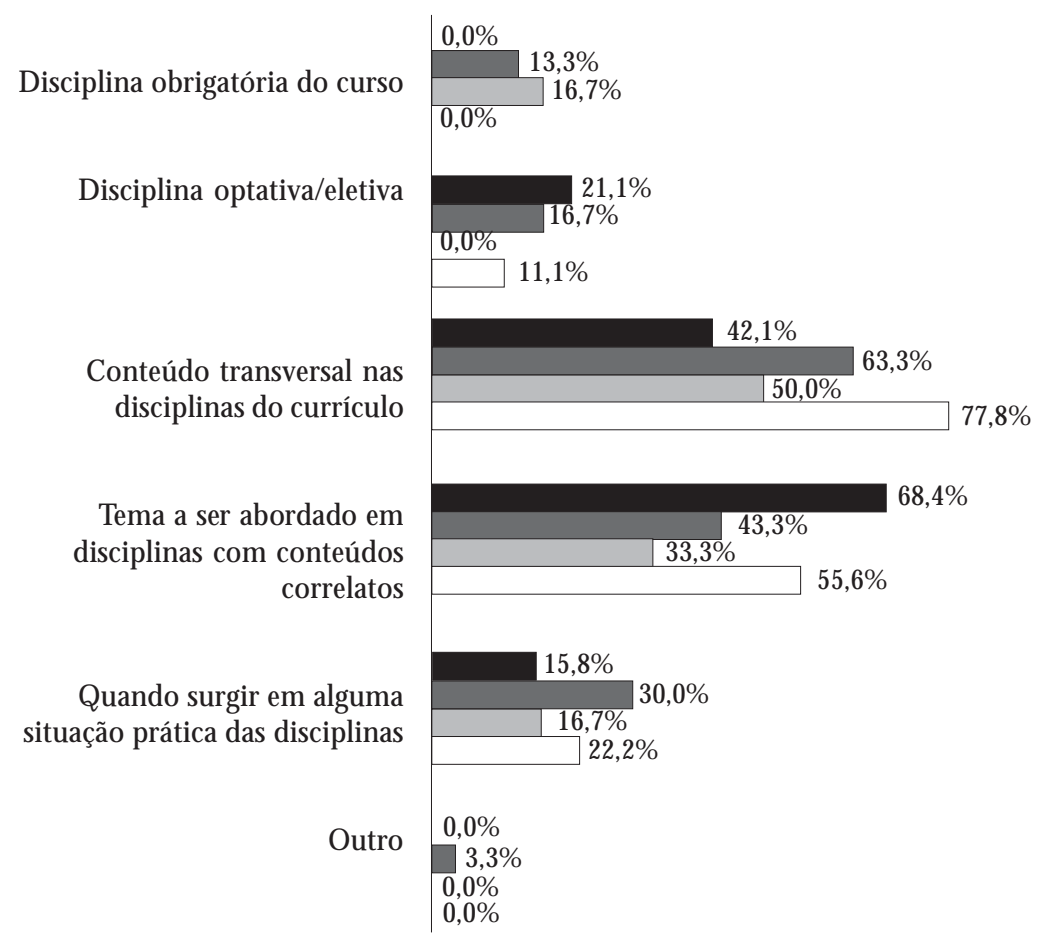

Rio de Janeiro - Medicina

Rio de Janeiro - Enfermagem

$\square$ Cuiabá - Medicina

Cuiabá - Enfermagem

Gráfico 3. O pinião dos docentes sobre a forma de incorporação do tema da violência intrafamiliar na formação dos alunos.

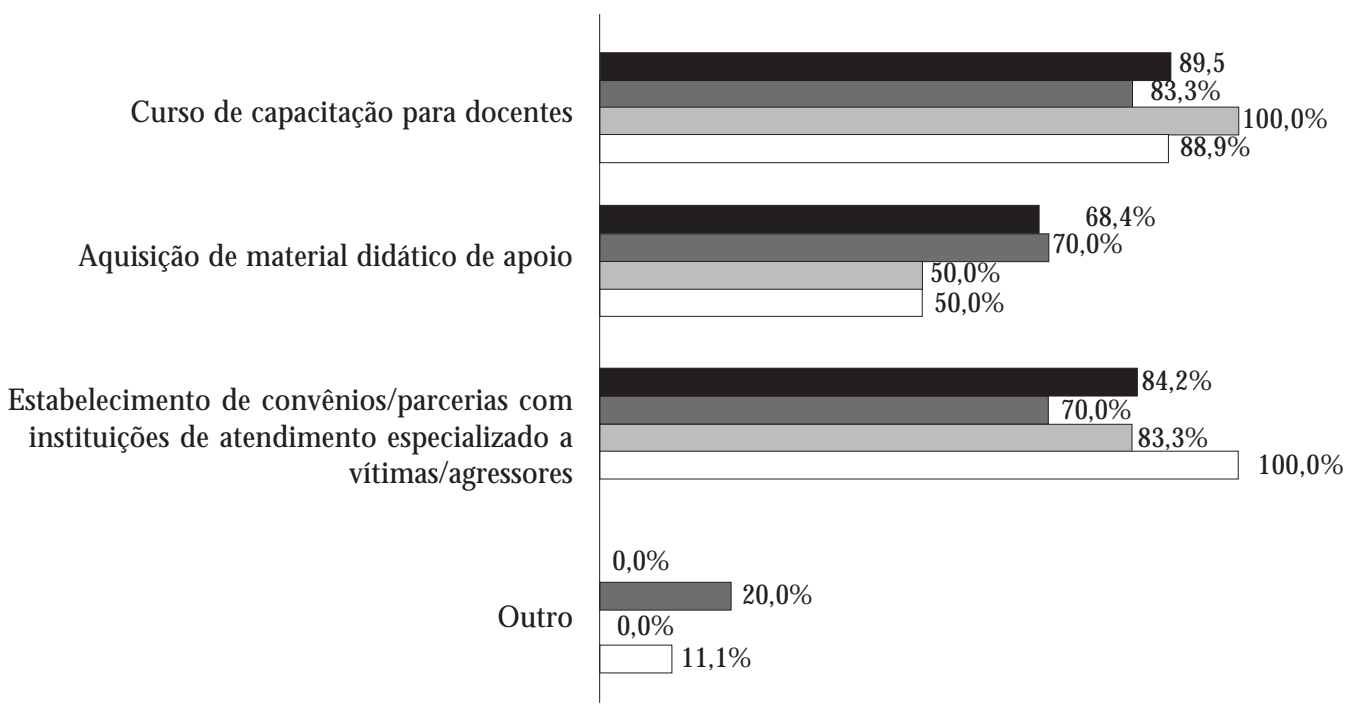

Rio de Janeiro - M edicina

Rio de Janeiro - Enfermagem

Cuiabá - Medicina

Cuiabá - Enfermagem

Gráfico 4. Sugestões dos docentes sobre os recursos que consideram importantes para a formação dos alunos. 
Além disso, o estabelecimento de convênios e parcerias com instituições de atendimento especializado a vítimas e agressores como Conselho Tutelar, SOS Criança, SOS M ulher, Delegacia Especializada e Instituto M édico Legal foi uma opção muito citada pelos docentes. Foi observada dife rença significativa entre os enfermeiros das duas cidades $(p=0,081)$ e os cariocas foram os que menos solicitaram essa estratégia.

A aquisição de material didático foi o recurso considerado menos importante pelos professores, principal mente entre os médicos de Cuiabá.

Os docentes sugeriram ainda outras opções, como o trabalho interdisciplinar entre os alunos dos cursos de enfermagem, medicina, psicologia, direito, serviço social, história e filosofia; cursos e projetos de extensão para alunos/profissionais que discutam politicamente a questão; estudos entre alunos e docentes sobre o tema; parceria com movimentos sociais, organizações não governamentais e representações populares que trabal ham com a violência intrafamiliar. Também houvequem afirmasse que esse tema já vem sendo abordado na especialização de saúde mental.

Ao investigar, em uma das questões abertas, qual a visão dos docentes sobre as ações que eles julgam que suas faculdades têm condições de de senvolver para preparar os alunos na prática de atenção eprevenção da violência intrafamiliar, observamos que as suas sugestões envolvem várias possibilidades que já poderiam estar sendo adotadas. Suas respostas foram agrupadas e estão explicitadas nos itens a seguir.

\section{Ações relacionadas à assistência}

Estabelecer parcerias/convênios com instituições que lidam com a violência para inserção dos alunos; fazer grupos com população de risco que frequenta o hospital; atender às famílias, vítimas e agressores; desenvolver atividades educativas de sala de espera com os alunos no ambiente hospitalar; realizar treinamento em ambulatório especializado; promover contato dos alunos com profissionais que lidam com o problema em atividades extramuros e com alunos de outros cursos.

Ações relacionadas ao ensino de graduação

Inserir o conteúdo no currículo da graduação em disciplinas que envolvem grupos-alvo ou que tenham interface com o tema (saúde pública, psicologia, doenças infecto-parasitárias, entreoutras); criar disciplina que trate do tema ou inseri-lo de forma transversal em outras disciplinas; promo- ver seminários internos; sensibilizar e formar alunos aptos a lidar com o ser humano em suas individualidades e especificidades e capazes de adotar estratégias e atitudes para resolver situações conflitantes na prática profissional; abordar a temática da violência a partir da discussão ética da desigualdade; desviar o foco do ensino, do atendimento de pacientes internados para 0 atendimento primário em serviços de emergência, onde as situações são mais detectadas; promover grupos de estudo; adquirir e elaborar material didático como filmes eliteratura.

\section{Ações relacionadas à extensão}

Organizar diversas modalidades de eventos sobre o tema (seminários, cursos de atualização para profissionais de saúde); trabal hos educativos em comunidades e postos de saúde; organizar projetos de extensão relativos ao tema; participar de frentes e fóruns populares sobre a questão; elaborar capacitações com ações integradas das áreas do direito, medicina, assistência social, psicologia e outras; participar de atividades com alunos e professores de primeiro grau.

\section{Ações relacionadas à pesquisa}

Estimular projetos de pesquisa e a produção científica sobre a temática, envolvendo os alunos;

Ações de formação/educação continuada para os docentes

Organizar eventos sobre o tema no espaço da universidade e cursos de capacitação para professores; divulgar as ações em desenvolvimento na universidade para os alunos e promover intercâmbio entre os cursos da faculdade.

Conforme pudemos perceber, os docentes demonstram em respostas bastante diversificadas que a faculdade tem muito como contribuir para a formação de seus alunos no tocante ao tema aqui estudado. As sugestões dadas pelos professores revelam ações possíveis de serem executadas e que requerem planejamento e organização das universidades para que o tema seja discutido nesse espaço de formação dos profissionais que irão atuar na rede pública de saúde.

Finalmente, foi solicitado aos docentes que apontassem as lacunas que julgam haver na formação dos alunos em relação à temática. Em suas opiniões, fica clara a existência de diversas limitações, tanto na formação do aluno como na do professor. Chama atenção o número de respostas que 
dizem que o tema não é abordado na graduação ou o é de forma insuficiente e superficial.

$\mathrm{Na}$ visão desses atores, as dificuldades na formação dos alunos localizam-se na falta de conteúdo específico e de sistematização de conhecimentos sobre violência. Quando abordado, o é de forma pontual, difusa e pouco aprofundada, sem relação com o programa curricular. Também não é abordado formalmente nas atividades práticas. Este, assim como outros temas como uso de drogas, sexualidade, relação médico-paciente, abordagem do pacienteterminal e do paciente psiquiátrico, ainda é discutido de forma aberta. Sintetizam afirmando que falta obrigatoriedade do ensino teórico e prático sobre o tema. N este sentido, é importante ressaltar que alguns deles se posicionaram contra a existência de uma disciplina obrigatória específica sobre violência, mas isso não impede que o tema seja obrigatoriamente inserido em outras disciplinas, de modo transversal e em disciplinas com conteúdos afins.

Os professores consideram que as especialidades têm muito conteúdo a ser abordado enão conseguem inserir mais um tema como este. N esse sentido, acham que seria necessário rever o planejamento dos currículos e afirmam, criticamente, que há pouca ou nenhuma interlocução entre os representantes das áreas que compõem o currículo e os professores.

Segundo eles, os alunos e docentes deveriam ter condições de segurança e acesso ao Programa de Saúdeda Família (PSF), comunidades eescolas para vivenciar a realidadedo problema. No entanto, devido à violência urbana, os alunos ficam afastados doscampos de prática. A existência depoucos locais de atendimento onde 0 graduando possa estagiar dificulta a aproximação deles ao atendimento e às intervenções necessárias aos casos de violência, levando os alunos, despreparados, a basear suas condutas em sua bagagem de vida. Curiosamente, para eles, faltam espaços acadêmicos para discutir política efilosoficamente a violência, como sea universidade não se constituísse como tal, o que caracteriza a dicotomia entre teoria e prática. Ressaltaram também a pouca interação entre as instituições formadoras e as unidades de cuidado e proteção.

Ainda em relação à formação dos alunos/profissionais de saúde, os professores afirmam que há desorganização do sistema de saúde em geral (como, por exemplo, pessoas não atendidas, falta de médicos), levando ao descrédito do profissional. Também destacam a pouca visibilidade do problema por falta de dados, de material didático e de incentivo à leitura de jornais e revistas que forneçam subsídios para as discussões.
Outra dificuldade apontada é a percepção de que a violência ainda é tida como "algo gestante" ou como "assunto de família". Reconhecem a não valorização do tema, admitindo que talvez isso ocorra por não existir uma solução pronta, como um medicamento facilmente prescritível para o problema. Julgam que a atenção básica também não valoriza a abordagem das questões relativas à violência e dão maior enfoque à atenção hospitalar. Para eles, o modelo biomédico de ensino continua muito presente ena anamnese, por exemplo, as condições socioeconômicas, psicológicas e culturais, o relacionamento familiar e as demandas psicossociais ficam em segundo plano em detrimento das questões biológicas do paciente, sobretudo na formação médica.

Por outro lado, em relação à formação dos docentes, uma das dificuldades citadas pelos próprios professores é o desconhecimento de onde conseguir apoio e recursos da comunidade para prestação de assistência. Reclamam da falta de informações que contribuam para a formação dos alunos, sobretudo do M inistério e das Secretarias de Saúde. A pouca capacitação profissional, atualização e re ciclagem, aliada à pouca literatura disponível e ao medo de lidar com as questões da violência (sobretudo das situações íntimas), levam professores e profissionais a não se aprofundarem no tema.

Os docentes também apontaram a falta de experiência para lidar com as vítimas, para acolher $\mathrm{e}$ atuar junto à criança, ao adolescente, à família vítima de violência e atender ao agressor.

Consideram que Ihes faltam metodologias para desenvolver uma abordagem prática do tema, principalmente quando o campo de ensino clínico éa rede hospitalar.

\section{Consideraçõesfinais}

Diferente de outros problemas de saúde, a complexidade que envolve o tema da violência requer que sua abordagem no âmbito da atenção em saúdetambém seja complexa. Não setrata simplesmente de cuidar de ferimentos, mas de fornecer uma escuta qualificada, o apoio necessário e uma equipe apta a realizar um atendimento mais integral.

É imprescindível ressaltar o ineditismo e a importância deste trabalho no momento em que as universidades brasileiras encontram-se reformulando seus projetos político-pedagógicos e que 0 M inistério da Saúde está investindo na implementação da Política de Prevenção da Morbimortalidade por Acidentes eV iolência e do plano de ação 
para a implementação da mesma, sendo todos extremamente enfáticos com a questão da formação dos profissionais de saúde para 0 atendimento qualificado aos agravos provocados à saúde pela violência.

Ao abordar a inserção da temática violência intrafamiliar no planejamento curricular dos cursos degraduação em medicina e enfermagem através da visão dos docentes, pensamos que este estudo é de grande relevância. Ele coloca em debate a formação destes atores e desencadeia a discussão sobre a introdução de temas sociais complexos na formação de profissionais da saúde, que repercutem direta eindiretamente na saúde da população, como é o caso da violência. Temas desta natureza, que demandam uma abordagem interdisciplinar e intersetorial, funcionam como "analisadores institucionais", mostrando as próprias limitações dos currículos de formação profissional.

As políticas públicas demodo geral, e as específicas deatenção eprevenção dos acidentes eviolências, dirigidas à criança eao adolescente, à mulher, ao idoso e outros grupos vulneráveis, enfatizam o importante papel da inserção do tema no âmbito do ensino nos diversos níveis devido à sua magnitude e impacto na saúde da população brasileira. Às políticas agregam-se leis como os Estatutos da Criança e do Adolescente e o do Idoso, que destacam que a violência precisa ser enfrentada e uma forma de fazê-lo é sensibilizando, conscientizando, capacitando e formando pessoas dos mais diversos âmbitos da sociedade, mas, sobretudo, os alunos e profissionais do setor saúde, para onde convergem as vítimas desses eventos.

Entretanto, o conhecimento advindo do presente trabalho mostra que, mesmo diante dos ele vados índices de violência na realidade brasileira, das orientações do SUS, das políticas específicas sobre violência e das universidades que formam profissionais capacitados para atender aos principais problemas de saúde da população, ainda é incipiente nessas últimas o debate e a apropriação desse tema em suas grades curriculares.

Sabemos que as mudanças curriculares não ocorrem sem políticas específicas e que, mesmo quando estas são criadas, levam um bom tempo para assimilação do corpo docente, que resi ste sob o impacto do modelo de sua própria formação profissional.

Este estudo conseguiu trazer à tona al guns pontos fundamentais a partir das falas dos professores, tais como o medo e a falta de treinamento e capacitação do corpo docente para a abordagem da violência.

A partir desses achados, é preciso não só desencadear formas de suprir tal lacuna na formação do docente, mas também de inovar nas metodologias e conteúdos, incluindo a possibilidade de verbalização dos medos e trabalho de fortalecimento pessoal eprofissional para lidar com o tema.

É preciso realçar que os estudantes necessitam ser incentivados a desenvolver a consciência crítica das forças sociais maiores que afetam a vida e a saúde, e a reconhecer o seu papel potencial como membro de uma comunidade que se posiciona contra a violência. M as esse incentivo e essa consciência cidadã dependem, em grande medida, dos docentes que atuam diretamente nesta formação.

Finalmente, éimportante destacar a necessi dade deintegração ecoerência entreas diretrizes preconizadas nas políticas públicas e as diretrizes básicas da educação no sentido de capacitar os alunos, futuros profissionais para o enfrentamento dos problemas sociais e de saúde para os quais necessitam ter uma consciência crítica que possibilite a superação dos mesmos.

\section{Colaboradores}

ER Souza eAP Ribeiro participaram da concepção, análise dos dados e escrita do artigo. AL Ferreira contribuiu com a análise dos dados e a revisão final. LH GPenna, CM M Tavares e NC Santos contribuíram com a revisão do artigo. 


\section{Referências}

1. Rosenberg M L, Fenley MA, Johnson D, Short L. Bridging prevention and practice: public health and family violence. Acad M ed 1997; 72(Suppl.):S13-S18.

2. Short LM, Cotton D, Hodgson CS. Evaluation of the module on domestic violence at the UCLA School of Medicine. Acad M ed 1997; 72(Suppl.):S75-S92.

3. Weiss LB, Kripke EN, Coonse HL, O'Brien MK. Integrating a domestic violence education program into a medical school curriculum: challenges and strategies. Teach Learn M ed 2000; 12:133-40.

4. Carney DM, MCKibbin L. Screening for domestic violence. N urs M anage 2003; 34:35-36.

5. M inayo MCS, Souza ER, M alaquias JV, Reis AC, Santos NC, Veiga JPC, Silva CFR, Fonseca IG. Análise da morbidade hospitalar por lesões e envenenamentos no Brasil em 2000. In: M inayo M CS, Souza ER, organizadoras. Violência sob o olhar da saúde: a infrapolítica da contemporaneidade brasileira. Rio de Janeiro: Fiocruz; 2003. p.109-130.

6. Souza ER, Lima M LC. The panorama of urban violence in Brazil and its capitals. Cien Saude Colet 2006; 11(2):363-374.

7. Reid SA, Glasser M. Primary care physicians' recognition of and attitudes toward domestic violence. Acad M ed 1997; 72:51-53.

8. Cullinane PM, Alpert EJ, Freund KM. First-year medical students' knowledge of, attitudes toward, and personal histories of family violence. Acad M ed 1997; 72:48-50.

9. Hendricks-M atthews MK. A survey of family-violence curricula in Virginia medical schools and residencies at university medical centers. Acad M ed 1997; 72:5456.

10. Dickstein LJ. Practical recommendations for supporting medical students and faculty in learning about family violence. Acad M ed 1997; 72(Suppl.):S105-S109.

11. Gonçalves HS, Ferreira AL, Marques MJV. Avaliação de serviço de atenção a crianças vítimas doméstica. Rev. Saude Publica 1999; 33:547-553.

12. Raul M, Aleman M, Fernandez A, Perez Stable EJ. Conocimientos y detección de violencia domestica por los médicos clínicos. Medicina (B. Aires) 2000; 60:591-594.

13. Day VP, Telles LEB, Zoratto PH, Azambuja MRF, $M$ achado DA, Silveira MB, Debiaggi $M$, Reis MG, Cardoso RG, Blank P. Domestic violence and its manifestations. Rev Psiquiatria-RGS 2003; 25:9-21.

14. Brasil. Ministério da Educação e Cultura. Diretrizes Curriculares Nacionais dos Cursos de Graduação em Enfermagem, M edicina e Nutrição. Parecer CNE/CES 1.133. Brasília: M inistério da Educação e Cultura; 2001.
15. Brasil. Portaria no 936/GM, de 18 de maio de 2004. Dispõe sobre a estruturação da Rede Nacional de Prevenção da Violência e Promoção da Saúde e a Implantação e Implementação de Núcleos de Prevenção à Violência em Estados e M unicípios. Diário Oficial da União 2004; 20 mai.

16. Brasil. M inistério da Saúde. Violência intrafamiliar: orientações para a prática em serviço [Caderno de Atenção Básica n 8]. Brasília: Ministério da Saúde; 2002.

17. Brasil. M inistério da Saúde. Secretaria de Vigilância em Saúde. Política nacional de promoção da saúde [Textos básicos de saúde, série B]. Brasília: M inistério da Saúde; 2006.

18. Minayo MCS, Deslandes SF. Acidentes e violências na pauta política do setor saúde: análise diagnóstica de institucionalização [relatório final de pesquisa]. Rio de Janeiro: CLAVES; 2007.

19. Cabral IE, Souza IEO, Coelho MJ. Projeto pedagógico de enfermagem e a formulação das diretrizes curriculares para o curso de graduação: uma análise crítica. Caderno CE 2002; 5(3):88-104.

20. Penna LHG. A temática da violência contra a mulher na formação da enfermeira [tese]. Rio de Janeiro (RJ): Instituto Fernandes Figueira, Fundação O swaldo Cruz; 2005.

21. Woodtli MA, Breslin E. Violence-related content in the nursing curriculum: a follow-up national survey. J Nurs Educ 2002; 41:340-348.

22. Pursley HG, Kwolek DS, Griffith CH, Wilson JF. Women's health issues and residents' knowledge. J Ky Med Assoc 2002;100: 238-244.

23. Costa HOG. A problematização da violência como experiência de ensinar em saúde. Interface (Botucatu) 1999; 3(5):63-74.

24. Brasil. Portaria MS/GM no 737, de 16 de maio de 2001. Política Nacional de Redução da Morbimortalidade por Acidentes e Violências. Diário Oficial da União 2001; 18 mai.

Artigo apresentado em 17/10/2007

Aprovado em 27/06/2008 